\title{
O conceito de opinião pública na teoria da comunicação: genealogias e modos de abordagem ${ }^{1}$
}

Public opinion concept pathways in communication theory: genealogies and axes of approach

El concepto de opinión pública en la teoría de la comunicación: genealogías y formas de abordaje

\section{(9) Luis Mauro Sá Martino}

- Doutor em Ciências Sociais pela Pontifícia Universidade Católica de São Paulo (PUC-SP).

- Pesquisador-bolsista na Universidade de East Anglia, na Inglaterra.

- Autor dos livros Métodos de pesquisa em comunicação (2018), Teoria da comunicação (2009), Comunicação e identidade (2010) e The mediatization of religion (2016).

- Publicou, em co-autoria com Ângela Marques, o livro Ética, mídia e comunicação(2018).

- Professor do programa de pós-graduação em Comunicação da Faculdade Cásper Líbero.

- E-mail: Imsamartino@gmail.com

\section{(9) Ângela Cristina Salgueiro Marques}

- Pós-doutora pela Universidade Stendhal, Grenoble III, na França.

- Doutora em Comunicação Social pela Universidade Federal de Minas Gerais (UFMG).

- Autora dos livros Apelos solidários (2017), escrito com Angie Biondi; Diálogos e dissidências: M. Foucault e J. Rancière (2018), com Marco Aurélio Prado e Ética, mídia e comunicação (2018), com Luis Mauro Sá Martino.

- Organizadora do livro Vulnerabilidades, justiça e resistências nas interações comunicativas (PPGCOM, 2018).

- Professora do programa de pós-graduação em Comunicação da UFMG.

- E-mail: angelasalgueiro@gmail.com 


\section{Resumo}

Qual é o lugar do conceito de "opinião pública" na teoria da comunicação? Embora seja um dos assuntos mais antigos e abordados com mais frequência nos estudos de mídia, parece não haver consenso a respeito de seu significado, extensão ou limites. Este artigo descreve algumas das atuais concepções de opinião pública desenvolvidas na pesquisa em mídia. A partir de pesquisa bibliográfica, em abordagem genealógica, o texto sugere a existência de três correntes principais, cada uma conferindo à mídia e à comunicação um lugar diferente. Observa-se, dessa maneira, a opinião pública entendida superficialmente como resultado de uma influência da mídia mais ou menos limitada, que reflete, também, as concepções anteriores das pessoas sobre um assunto. Além disso, ela é conceituada como disputa ideológica de interesses e produto da conversa racional de pessoas livres sobre questões públicas. Esses elementos são discutidos no contexto da pesquisa em mídia e política.

PALAVRAS-CHAVE: OPINIÃO PÚBLICA • MÍDIA • COMUNICAÇÃO • GENEALOGIA•EPISTEMOLOGIA.

\section{Abstract}

What is the role of 'public opinion' in communication theory? Although it is one of the oldest and most frequently addressed subjects in media studies, there seems to be a lack of consensus about what exactly it means. This paper outlines some of the current conceptions of 'public opinion' in media research. Grounded on bibliographical research in a genealogical approach, this paper argues that three main currents, or 'traditions', have emerged so far regarding the notion of 'public opinion': as a result of a more or less limited media influence that also mirrors people's previous conceptions on a subject; and also as the product of ideological dissent or rational conversation by free people regarding public matters. These elements are discussed against the background of media and politics research.

\section{KEYWORDS: PUBLIC OPINION・MEDIA・COMMUNICATION・GENEALOGY・EPISTEMOLOGY.}

\section{Resumen}

¿Qué lugar ocupa el concepto de "opinión pública" en la teoría de la comunicación? A pesar de ser uno de los temas más antiguos y más abordados en los estudios sobre los medios de comunicación, no parece haber consenso en cuanto a su significado, extensión o límites. Este artículo describe algunas de las concepciones actuales de la opinión pública desarrolladas en la investigación de los medios de comunicación. A partir de una investigación bibliográfica, de enfoque genealógico, el texto evidencia la existencia de tres corrientes principales, cada una otorga a los medios y la comunicación un lugar distinto. En este contexto, la opinión pública se entiende de manera superficial como el resultado de una influencia mediática más o menos limitada, que también refleja las concepciones previas de las personas sobre un tema. Además, la conceptualiza como una disputa ideológica de intereses y resultado de la conversación racional de personas libres sobre temas públicos. Esos elementos se discuten en el contexto de la investigación de los medios de comunicación y política. 
$\mathrm{P}$ oucos conceitos têm uma trajetória de estudos tão longa na área da comunicação quanto a noção de "opinião pública" percurso comparável apenas a outra qualidade sua: a ausência de um consenso a respeito de seu significado, como indicam Gomes (2001) e Marques (2017). A palavra possui uma ampla circulação não apenas nos meios acadêmicos, mas também no jornalismo, na política e nas mídias digitais - quando se fala, por exemplo, em "formadores de opinião", "influenciadores" ou "digital influencers".

Na comunicação organizacional, a preocupação com a opinião pública é uma das matrizes para pensar a atuação profissional. Isso se reflete em uma produção teórica que aproxima relações públicas, comunicação organizacional e opinião pública, seja ao redor de modelos teóricos ou de estudos de caso. Dentre os trabalhos recentes, ilustram essa tendência as pesquisas de Cruz (2007), Esteves (2010), Marques e Almeida (2015) e Souza (2019), além de um panorama que pode ser visto no livro de Farias, Lemos e Rebechi (2020).

Em termos gerais, nos estudos de comunicação, a ideia de "opinião pública" encontrou um terreno fértil para se desenvolver na medida em que, como lembram Signates (2012) e Champagne (1998), não é possível pensar a democracia sem levar em consideração as formas, condições e possibilidades de comunicação existentes nela. Como recorda Loïc Blondiaux (2001, p.12) na introdução de um número especial da revista Hermès sobre opinião pública, esse esforço genealógico não é no sentido de fazer um "inventário de ruínas", mas trazer textos "vivos, regularmente citados e editados no mundo anglo-saxônico".

Uma aproximação inicial do conceito permite observar a recorrência de algumas palavras: "opinião" e "público", "influência" e "formação" caminham próximas, permitindo entrever alguma ligação entre elas. No entanto, a natureza desse vínculo está longe de ser observável empiricamente, o que desafia tentativas de definição mais rigorosas.

Revisões conceituais do tema têm sido feitas periodicamente, como em Figueiredo e Cervellini (1995), Gomes (2001), Price (2011) ou no trabalho de Mora y Araujo (2012). Por seu turno, Carla Longhi (2006), Nilza de Sena (2007) e John Nerone (2015) trabalham a questão em perspectiva histórica, desenvolvendo uma argumentação que mostra os movimentos da noção de opinião pública em relação aos sistemas midiáticos existentes em cada ocasião. Próximo a este texto, o trabalho de Fernanda Vasques Ferreira (2015) também estuda o lugar do conceito de opinião pública na pesquisa em comunicação. A autora trabalha em uma perspectiva histórica, com a qual se dialoga aqui.

A ideia aqui é, a partir de pesquisa bibliográfica, trabalhar com fragmentos cartográficos dos movimentos do conceito no discurso teórico da comunicação - mais do que propor uma definição. A partir desses procedimentos, é possível observar três polos discursivos relacionados ao conceito de "opinião pública" nos estudos de Comunicação: (1) a opinião pública como decorrência da ação da mídia sobre um público mais ou menos difuso; (2) a formação da opinião pública como interação entre cidadãos na perspectiva de um uso público da razão e (3) a opinião pública como disputa de sentidos que se estruturam em um jogo estratégico no qual perdura uma forma de comunicação distorcida e ideológica. Elas se desenvolveram de forma mais ou menos paralela ao longo do século XX e início do século XXI, e não faltam, evidentemente, pontos de contato. Há origens comuns, como a filosofia social inglesa do século XVIII e a sociologia franco-alemã do século XIX que, devido ao foco deste trabalho, não serão detalhadas.

No que se segue, 0 artigo delineia fragmentos genealógicos de cada um desses discursos teóricos. 


\section{A OPINIÃO PÚBLICA COMO RESULTADO DA AÇÃO DA MÍDIA}

Talvez a tradição mais conhecida dos estudos sobre opinião pública seja aquela iniciada com a publicação, em 1922, de Opinião pública, de Walter Lippmann (2009). Embora estudos anteriores sobre comunicação mencionassem sua relação com a política e com a formação da opinião dos indivíduos, como nos trabalhos de Charles H. Cooley (1909), é sobretudo a partir de Lippmann que começa a tomar forma uma perspectiva de observar a intersecção desse tema com a mídia.

Lippmann dialoga, direta ou indiretamente, com estudos sobre opinião pública desenvolvidos sobretudo na segunda metade do século XIX ao redor das noções de "massa" e "multidão". Sendo categorias sociológicas de definição altamente problemática, essas ideias povoam, de certa maneira, várias análises a respeito das transformações sociais geradas pela modernidade, representada sobretudo pelo capitalismo industrial que se consolida naquele momento.

Com variações, essa noção torna-se não apenas dominante, mas também parte de um modelo de análise sociológica, ganhando uma ampla repercussão nos estudos de comunicação. A expressão "meios de comunicação de massa" ("mass media" em sua versão norte-americana), foi de uso corrente.

O conceito de opinião pública, nessa tradição, precisa dar conta de equilibrar um antigo problema, herdeiro das primeiras especulações sobre o tema na filosofia: qual a diferença entre "público" e "massa"? Se é possível falar de "opinião pública", existiria uma maneira de falar de "opinião da massa"? Há, sobretudo na sociologia de Tarde (1995), uma certa distinção entre a opinião de públicos específicos e a ausência de uma opinião que possa ganhar relevância política - ao mesmo tempo em que a massa não deixa de ter seu espaço nesse cenário.

Lippmann traz para essa equação um novo componente: os meios de comunicação. Capazes de atingir a "massa", são veículos de valores, crenças e ideias responsáveis pela formação de opiniões disseminadas indiscriminadamente por toda a população. Esse deslocamento, recordam Nerone (2015) e Silva (2016), indica uma mudança também no conceito de "público" na noção de opinião pública.

Em Opinião pública, Lippmann (2009) reserva à mídia um lugar central na formação das opiniões a partir das "imagens" que cria na mente das pessoas expostas à mensagem: um dos capítulos mais conhecidos do livro é sobre "estereótipos" - do grego "grande imagem" ou "imagem ampliada". Estereótipos, explica, são uma espécie de "atalho mental" criado pelos indivíduos como um elemento redutor da complexidade social, a partir do qual é possível entender rapidamente a realidade ao redor. A opinião pública, lembra Lippmann, é formada sobretudo a partir da disseminação, em grande escala, desses estereótipos. Vale observar que, para o autor, a mídia não é a responsável pela criação de estereótipos, mas sim por sua difusão.

Ao trazer a mídia para o debate sobre opinião pública, Lippmann não a coloca como detentora de um poder ilimitado, e sim de um fator relevante na formação da opinião pública. Trata-se de uma opinião "em massa", mas não necessariamente "das massas" na medida em que parece haver uma perspectiva vertical na maneira em que uma determinada ideia é colocada em circulação.

Lippmann desloca a discussão sobre opinião pública de sua matriz política e sociológica e a traz para os estudos de comunicação: se as mídias são responsáveis pela disseminação de estereótipos e pela formação da opinião pública, então é necessário investigar como isso acontece. Em Opinião pública(2009), isso é feito a partir do estudo das características da mídia (em particular do jornalismo, da propaganda e do cinema) e da perspectiva de se trabalhar com o resultado da divulgação dessas informações sobre o público - a perspectiva de "efeitos" responsáveis pela formação da "opinião pública". 
Nos anos seguintes, o livro Opinião pública (2009) terá uma vasta descendência na pesquisa em comunicação política, trabalhando a partir da perspectiva de uma opinião pública ligada à mídia. Ao mesmo tempo, o trabalho não deixará de ser criticado por uma certa redução da autonomia da opinião pública, em referência ao elo formado com os meios de comunicação. Mais ainda, embora seja esboçada uma certa equivalência não exata entre "opinião da mídia" e "opinião pública", o nexo causal não é inteiramente provado ou justificado e, além disso, não contribui para uma definição específica do fenômeno da "opinião pública".

No entanto, nem as perspectivas críticas escapam de levar em consideração essa relação entre mídia e opinião pública. Os estudos de "efeitos", sejam "limitados" ou "ilimitados", se mostrarão devedores dessa perspectiva de Lippmann. Em termos genealógicos e institucionais, a perspectiva de conhecer os "efeitos" da mídia na opinião política se tornarão uma das áreas clássicas da comunicação política.

É interessante notar a persistência dessa ideia no pensamento comunicacional, por mais que ela seja alvo de debate e crítica ou que suas premissas e resultados sejam questionados. Trata-se, muitas vezes, aliás, de uma extrapolação ou exagero dessa ideia, conferindo à mídia um poder muito maior do que Lippmann (2009) define em seu livro. A noção de que a opinião pública é formada a partir da influência da mídia não só parece ter um amplo trânsito como também sobrevive praticamente intacta às mídias digitais, como diz Martino $(2010,2019)$.

Os trabalhos desenvolvidos uma geração depois, nos estudos de Paul Lazarsfeld (1975) a respeito dos limites da influência da mídia nas escolhas eleitorais, bem como as perspectivas de Bernard Berelson (1952) a respeito das delimitações do próprio conceito de "opinião pública" dentro de uma sociedade marcada pela presença dos meios de comunicação.

Seus trabalhos conjuntos são responsáveis por uma mudança de direção nas pesquisas da área: The people's choice (1944) Voting (1954) e Personal influence (1955) formam uma espécie de trilogia - tendo em comum a participação de Lazarsfeld referente à formação da opinião pública na interação entre pessoas e seus grupos imediatos, como família ou trabalho, mais do que dependente de uma influência direta da mídia.

Não é coincidência, em termos epistemológicos, que as relações entre mídia e opinião pública sejam estudadas a partir de um diálogo com a psicologia social e outras ciências do comportamento. As metodologias de estudo empregadas são majoritariamente empíricas e, em certa medida, quantitativas. Como Lazarsfeld (1975) ressalta, a abordagem empírica não deixa de lado o diálogo com toda a tradição teórica e especulativa, precedente e contemporânea.

Nas décadas seguintes, as pesquisas sobre opinião pública vinculadas a essa tradição encontrarão novos caminhos, mas não chegarão a se afastar definitivamente dessa trilha. Essa continuidade pode ser observada mesmo em atualizações e revisões críticas do conceito, como em Schäfer e Taddicken (2015); Friemel (2015) ou Martino (2019), e se mantém como "paradigma dominante", avalia Riutort (2007).

As críticas a esse modelo são dirigidas, ao menos em parte, à dificuldade de aferir o lugar mídia no âmbito da formação da opinião pública. A presença de temas políticos na mídia não é garantia de participação ou engajamento na construção de uma opinião política. A formação da opinião pública, por exemplo, pode ser muito mais direcionada pelo interesse na vida privada de políticos do que em suas ideias, recordam Wojdynski e Riffe (2011), próximos à ideia de "escândalo político" de Thompson (2002). 0 engajamento com os outros na construção da opinião, indicam Chang (2011) e Rigotti (2012), depende também de uma identificação afetiva em termos de formação de grupo. A participação também parece estar intimamente ligada à disposição em discutir posições políticas, como indicam Gerber etal. (2013). 
Da mesma maneira, Nir (2011) indica que o grau de informação política tem uma relação com a perspectiva de engajamento em discussões - o que implica, como mostram Petersen, Slothuus e Togeby (2010), em problemas também na comunicação dos partidos políticos. Anne-Marie Gingras (1995, p.38, tradução nossa) sintetiza:

A ênfase sobre o domínio das técnicas relacionadas ao funcionamento da mídia permite identificar um certo número de mudanças nas práticas políticas, que identificarei a princípio da seguinte forma: é, em parte, o papel dos partidos políticos e o estabelecimento de prioridades políticas e, por outro lado, os fenômenos de personalização e dramatização².

Os estudos desenvolvidos nos anos 1960 e 1970 por Maxwell McCombs (1972) e a hipótese do "agenda-setting", bem como a ideia de "espiral do silêncio", de Elizabeth Noelle-Neuman (1979) ou o "efeito de terceira pessoa", desenvolvido por Philips Davison (1983), retomam não apenas a ideia de uma influência da mídia na formação dos temas de discussão e da opinião pública, mas procuram mostrar novas dinâmicas desse processo. Nos estudos anglo-saxões, essa perspectiva relacionada a uma visão de influência da mídia parece se manter nos limites de uma genealogia que procura determinar os parâmetros desse processo.

\section{A COMUNICAÇÃO INTERPESSOAL COMO FORMAÇÃO DA OPINIÃO}

Uma perspectiva que rivaliza fortemente com aquela desenvolvida por Lippmann é a de John Dewey que, em 1927, publica A opinião pública e seus problemas. Segundo Dewey, problemas que atingem uma coletividade produzem um tipo especial de interação entre aqueles diretamente implicados, conduzindo-os a debates e conversações nas quais tentam melhor definir o que os atinge e buscam resposta para os dilemas enfrentados. Ainda que vários desses dilemas exijam um tratamento institucional e legal, o surgimento de um "público" em torno deles traz, segundo Dewey, uma grande contribuição para a democracia:

Os seres individuais agem juntos. A ação de cada ser se produz juntamente com a ação dos demais. Esse "em conjunto" significa que a conduta de cada um se modifica por sua conexão com os demais. [...] 0 que há de discutível sobre a associação humana é como chegam a vincular-se de um modo que traz às comunidades humanas traços diferentes de outras formas de associação. 0 fato de se observar os efeitos da ação conjunta obriga os homens a refletir sobre sua própria conexão; convertendo-a em objeto de atenção e interesse. Na medida em que se percebe a conexão, todos atuam seguem pensando, conversando, desejando e mostrando objetivos, mas pensam também nas consequências que sua conduta produz na conduta coletiva ${ }^{3}$. (Dewey, 2004, p.69, tradução nossa)

Um público se forma quando um conjunto de pessoas, preocupadas com aspectos políticos da vida social, participa da vida política coletiva por meio de debates e discussões através dos quais definem um "problema" que deve ser tratado em comunidade (Silva, 2016). Assim, a formação de um público está sempre intimamente ligada aos modos como problemas coletivos são definidos e tratados (Blumer, 1967; Speier, 1972). "Somente quando se permite o livre jogo dos fatos para que surjam novos pontos de vista em discussão torna-se possível alguma mudança importante de convicção com relação ao significado"4 (Dewey, 2004, p.59, tradução nossa).

\footnotetext{
2 Do original: «L'emphase sur la maitrise des techniques reliées au fonctionnement médiatique permet 'identification d'un certain nombre de changements dans les pratiques politiques, que j'identifierai dans un premier temps: il s'agit d'une part du rôle des partis politiques et de l'établissement des priorités politiques et d'autre part des phénomènes de personnalisation et de dramatisation.»

3 Do original: "Los seres individuales actúan juntos. La acción de cada ser tiene lugar junto con la acción de los demás. Este 'en conjunto' significa que la conducta de cada uno se modifica por su conexión con los demás. [...] Lo que es discutible acerca de la asociación humana es cómo llegan a vincularse de una manera que aporta a las comunidades humanas rasgos diferentes de otras formas de asociación. Observar los efectos de la acción conjunta obliga a los hombres a reflexionar sobre su propia conexión; convirtiéndola en objeto de atención e interés. En la medida en que se percibe la conexión, todos trabajan pensando, hablando, deseando y mostrando metas, pero también piensan en las consecuencias que su conducta produce en la conducta colectiva."

4 Do original: "Solo cuando se permite que los hechos jueguen libremente para que se puedan discutir nuevos puntos de vista, se puede hacer posible un cambio importante de convicción sobre el significado."
} 
No final da década de 1950 e início dos anos 1960, outra tradição de estudos, em diálogo com a reflexão de Dewey, ganhava forma na síntese original de Jürgen Habermas (2011) em seu livro Mudança estrutural da esfera pública. Escrito originalmente como tese de doutorado sob orientação de Theodor Adorno, o livro foi publicado no início dos anos 1960 e desloca a "mídia de massa" de seu ponto central como instrumento de formação da opinião para focalizar em um processo histórico e social mais amplo, em que o próprio conceito de "mídia" é alterado, colocando em destaque a interação entre as pessoas - a conversação.

Habermas retoma uma ideia de opinião pública tal como existia em um momento anterior ao surgimento do cinema, do rádio e da televisão, situando a origem do fenômeno - e do conceito - no século XVIII, imediatamente antes da Revolução Francesa. Ao deixar de lado a discussão sobre a mídia contemporânea e investigar o nascimento da opinião pública, Habermas (2011) sublinha o espaço do jornalismo e, em uma escala menor, da literatura - mídias dominantes do período histórico que focaliza. 0 cenário também muda: se no modelo anterior a relação era entre indivíduos, grupos e a mídia, nesse outro momento a opinião pública é formada na conversação política entre os cidadãos. Habermas desloca o foco da formação da opinião pública da mídia, em sentido estrito como "meio", para a comunicação, entendida como interação conversacional entre os indivíduos.

Onde aconteciam essas conversas? Em um novo tipo de estabelecimento comercial que começa a se desenvolver no século XVIII e que se tornará típico do espaço urbano: o café. As casas de café, espaços de encontro, conversa e discussão, se afirmam como um local de discussão dos temas públicos (uma dos mais antigos ainda em funcionamento, a casa de chá Twinings, em Londres, data de 1706). Habermas destaca igualmente a circulação de livros, panfletos e toda uma literatura política, incluindo jornais de duração mais ou menos efêmera, como veículos para a disseminação das ideias que seriam debatidas pelos cidadãos.

A esfera pública, nesse momento, não é associada à visibilidade midiática de uma ideia, mas à conversação sobre temas políticos que se torna, em si, uma forma de atividade política. As discussões existiam como prelúdio à atividade política de uma classe que reivindicada um espaço cada vez mais amplo de participação nos negócios de Estado: a burguesia.

A legitimidade de um governo, vinda do "povo", encontra sua face mais visível na opinião pública: a negação, mais ou menos aberta, do "direito divino" dos reis de governar seu país, abrindo espaço para um novo tipo de legitimidade garantida pela "vontade do povo" e expressa na ideia de "opinião pública". À medida em que há uma transformação nas relações de produção, de uma economia marcadamente rural e baseada na renda da terra para a produção de mercadorias e, mais tarde, serviços relacionada à Revolução Industrial, o suporte de uma aristocracia fundiária deixa de ser suficiente para garantir a legitimidade do rei e as condições de seu governo.

Delineada dentro de uma perspectiva que se aproximará cada vez mais de um diálogo com Kant (1998) e sua concepção de um "uso público da razão" como característica da busca pelo entendimento e pela resolução de problemas políticos, a esfera pública apresentada por Habermas é ao mesmo tempo produtora e produto de sua época, o lluminismo.

Vale notar que o conceito de "povo" não se sustentava nos mesmos termos que hoje, séculos atrás. Como lembra María Cristina Menéndez (2009), se a democracia era o governo "do povo" ou legitimado por ele, essa noção de "povo" era restrita às pessoas que podiam ter alguma participação na vida política. Apenas os "representantes do povo" podiam, de fato, discutir em um lugar especial de fala, o parlamento. A dissociação entre governo e governados passa, no século XVIII, por uma transformação em termos das diferenças entre representantes e representados.

Como ampliar e tornar efetiva a participação e, sobretudo, trazer vozes historicamente marginalizadas para as discussões públicas? Gamson (1989) e Gastil (2008), por exemplo, questionam qual é o espaço da conversação política na tomada de decisões dentro da democracia deliberativa, em um sentido próximo ao quadro mostrado por Chappell (2012). 
Nos anos seguintes, uma série de questionamentos levam Habermas a reformular algumas de suas premissas, mantendo porém ampliando a ideia da deliberação pautada na comunicação livre entre indivíduos como lugar de formação da opinião pública. Uma das críticas mais famosas foi feita por Nancy Fraser (1990) em um texto apresentado em 1989 no congresso sobre Habermas e a Esfera Pública, na Universidade da Carolina do Norte (Chapel Hill). Os textos apresentados no evento foram editados e públicados por Craig Calhoun em sua obra Habermas and the public sphere (1991). Esse volume também contém a resposta que Habermas elaborou aos seus críticos, no texto "Further reflections on the public sphere". De maneira resumida, Fraser assinala que a paridade requerida por Habermas nos processos de formação da opinião pública exigiria a eliminação de desigualdades e de relações de poder e dominação, o que seria impossível. Para ela, "declarar que a esfera pública é uma arena deliberativa na qual não há distinções de status não é suficiente para revelar como as desigualdades influem no debate" (1990, p.60). Além disso, Fraser argumenta que existem arenas discursivas paralelas à esfera pública política burguesa nas quais membros de grupos marginalizados elaboram e fazem circular contra-discursos:

0 problema não é só a idealização que Habermas faz da esfera pública, mas também o fato de que ele falha em examinar outras esferas públicas não-liberais e não-burguesas. E é justamente porque ele não examina outras formas de esfera que ele idealiza a esfera pública burguesa [...]. Além de sempre ter existido essa pluralidade de públicos conflitantes, as relações entre públicos burgueses e os demais públicos sempre foram marcadas pelo desentendimento 5 . (Fraser, 1990, p.61, tradução nossa)

A reflexão feita por Fraser tem reflexos no pensamento de várias autoras feministas, como Mansbridge (2017) e Young (2001), que ressaltam a importância de destacar que múltiplas racionalidades estruturam múltiplas esferas públicas, se configurando a partir de lógicas próprias e laços de pertencimento que se definem por meio de demandas por reconhecimento pautadas em uma transformação radical de imaginários e quadros morais de avaliação das formas de vida. Rendido pelo pensamento feminista, Habermas admite que:

É incorreto falar de uma esfera pública singular, mesmo assumindo uma certa homogeneidade do público burguês... É preciso admitir a co-existência de esferas públicas concorrentes e apreender a dinâmica daqueles processos de comunicação que são excluídos da esfera pública dominante. [...] A cultura do povo ordinário não era apenas um pano de fundo, isto é, um eco passivo da cultura dominante, era também uma revolta violenta, periódica e recorrente, de um contra-projeto, distinto de um mundo de dominação hierárquico, com suas celebrações oficiais e disciplinas diárias [...] Às mulheres, tanto quanto a outros grupos, era negada uma participação ativa na formação da opinião e da vontade política6 ${ }^{6}$ (1992, p.425-428, tradução nossa)

Algumas dessas críticas, por exemplo em Herbst (1993), Mitra (2001), Dahlgren (2002) ou Tavares (2012), se endereçam sobretudo a essa concepção de opinião pública como algo que emerge da conversação. Eliasoph (1996) e Schudson (2001) problematizam a centralidade da conversação entre cidadãos para a formação da opinião pública. Em particular, Gomes e Maia (2008) e Maia etal. (2017) apontam essa dificuldade na conversação pública sobre toda uma variedade de temas de caráter mais pessoal ou na abordagens de questões sensíveis.

A esfera pública apresenta-se, dessa maneira, como o lugar de criação da opinião pública a partir da discussão entre cidadãos representantes de demandas e reivindicações a serem articuladas com as instâncias de decisão política. A opinião pública não

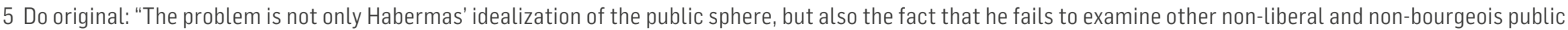

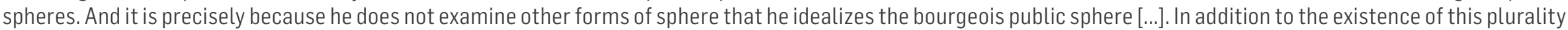
of conflicting audiences, relations between bourgeois audiences and other audiences have always been marked by disagreement".

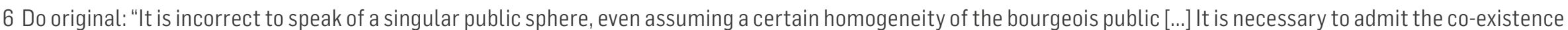

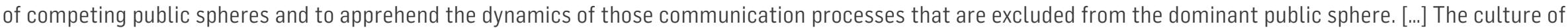

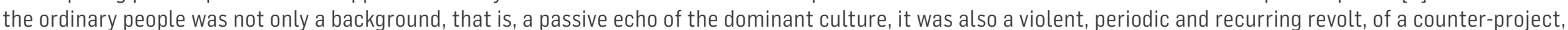

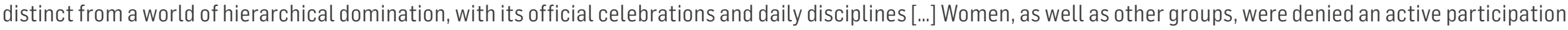
in shaping political opinion and will". 
só é formada pelo consenso e entendimento dos cidadãos, mas também se torna garantia de legitimidade - e principalmente apoio - das decisões governamentais.

Isso cria um problema que, de certa maneira, marca o desenvolvimento da obra de Habermas: qual o lugar da mídia? Por "mídia", no início da esfera pública, entendia-se sobretudo o jornalismo como espaço de "publicização" de ideias. Mas sabemos que, se nos anos 1960 Habermas condenava a mídia como instrumento de colonização do mundo da vida e de destruição da opinião pública crítica, nos anos 1990 ele já altera seu posicionamento, conferindo à mídia papel central na constituição de redes de esferas públicas:

A mídia de massa liberta os processos comunicativos dos contextos restritos e permitem que esferas públicas apareçam através do estabelecimento uma simultaneidade abstrata de uma rede virtualmente presente de conteúdos da comunicação que pode se mover no espaço e tempo tornando válidas mensagens para inúmeros contextos?. (Habermas, 1987, p.389, tradução nossa)

Como visto, a opinião pública é formada a partir da livre interação conversacional entre cidadãos que buscam algum tipo de entendimento ou consenso; mas é preciso ter em mente, nesse quadro, as dimensões do campo jornalístico, como recorda Champagne (1995), e seus desdobramentos na ampliação de um espaço público. Nas palavras de Rosario Sanchez Vilela (2014, p.35):

El espacio público expandido implica una doble ampliación: de accesibilidad y de alcance, ambos posibilitados por las tecnologías de la comunicación. Nuevos temas y grupos sociales se incorporan al espacio público al ser tomado por los medios de comunicación y se hace posible el acceso a su conocimiento. El fenómeno se vincula directamente con la expansión de los derechos y con la transformación de la tema misma de lo que es un derecho fundamental.

Essas opiniões, para se tornarem efetivamente "públicas", demandam um espaço para além do café ou do clube para alcançar uma visibilidade que aumente sua eficácia. Esse lugar só poderia ser o espaço da mídia - em particular do jornalismo. Isso traz a reboque um problema econômico: a sustentação econômica desse tipo de procedimento.

A progressiva dependência econômica do jornalismo na esfera pública em relação a outras instâncias da sociedade, na visão de Habermas (2011), mina sua possibilidade de uma efetiva participação nos negócios públicos - a opinião pública, que deveria emergir a partir das conversações, é progressivamente articulada ao caráter empresarial adotado pela mídia e, consequentemente, é sujeita às mesmas limitações e constrangimentos econômicos. Como recorda Sandra Valdettaro (1998, p.3), "mientras el ámbito de la opinión pública se amplía fenomenalmente via los medios masivos de comunicación, su función va perdiendo fuerzas. El carácter de lo público, con los medios, pierde su especificidad".

A internet, vista inicialmente como um espaço privilegiado para esse tipo de deliberação, mostrou rapidamente suas limitações, como apontam, entre outros, Dalhberg (2001), Papacharissi (2002), Savigny (2002), Stromer-Galley (2002), Dean (2003), Marques (2006) ou Mutz e Young (2011). Carolina Terra e Gisela Sousa (2020) retomam a questão no âmbito das redes sociais mostrando as readequações organizacionais nesse ambiente. Como destacam Natalia Raimondo Anselmino, María Reviglio e Ricardo Diviani (2015, p.220):

Si, por un lado, es evidente la visibilidad que adquieren una pluralidad de discursos a partir de las tecnologías de lo digital [...] se deja de lado la conformación de una esfera pública en el sentido que aquí nos interesa: es decir, a partir de la proliferación de discursos que hacen a la constitución de un público en el sentido político del término.

7 Do original: "Mass media frees communicative processes from restricted contexts and allows public spheres to appear through the establishment of an abstract simultaneity of a virtually present network of communication contents that can move in space and time making messages valid for countless contexts". 
É importante destacar que as conversações e debates que dão origem à opinião pública, sejam elas estabelecidas em contextos on-line ou off-line, são marcadas por desigualdades e assimetrias de poder que precisam ser tematizadas para que as normas que fundamentam a justiça possam ser alteradas. Young lembra que justiça não é apenas uma questão de revisão de normas e princípios, mas de escuta e respeito pelas singularidades e vulnerabilidades expressas nas demandas de grupos e sujeitos dos mais diversos tipos.

Se grupos oprimidos desafiam a suposta neutralidade de pressupostos e políticas prevalescentes e expressam suas próprias experiências e perspectivas, suas demandas são vistas como enviesadas, como interesses egoístas e especiais que desviam de um interesse geral e imparcial. 0 compromisso com um ideal de imparcialidade torna difícil expressar a parcialidade do ponto de vista supostamente geral, e também dificulta reclamar uma voz para os oprimidos ${ }^{8}$. (Young, 1990, p.116, tradução nossa)

A tematização das assimetrias de poder que interferem nos processos de formação da opinião pública tem sido alvo de reflexões de vários pesquisadores que atuam no campo da comunicação organizacional e institucional. As pesquisas recentes de Baldissera etal. (2016, 2020), Matos (2009, 2014, 2016), Weber (2017), Henriques (2015), Silva (2016) e Farias, Lemos e Rebecchi (2020) revelam uma preocupação comum: a atuação das forças de poder e a produção de vulnerabilidades que afetam os sujeitos e grupos que se engajam em espaços de discussão e conflito, afetando diretamente a formação da opinião pública e seus processos argumentativos.

\section{OPINIÃO PÚBLICA, VULNERABILIDADES E ASSIMETRIAS DE PODER}

Como ressaltam Baldissera etal. (2020), Henriques (2015) e também Farias, Lemos e Rebecchi (2020), várias podem ser as fontes de vulnerabilidades situadas em um contexto institucional: o não reconhecimento do trabalho executado; a falta de respeito; a execução de atividade insalubre e de risco; 0 assédio moral ou sexual; o racismo; 0 sexismo; a desfiguração decorrente da injúria etc. Eles ressaltam como as distinas vulnerabilidades e desigualdades que se manifestam situacionalmente e relacionalmente em contextos organizacionais impactam na constituição de espaços de discussão e debate e, consequentemente, nos processos de formação de públicos e da opinião pública dentro e fora desses contextos. Além disso, elas revelam processos de injustiça sustentados institucionalmente, moralmente e imaginariamente para avaliar, julgar e reconhecer vidas e modos de vida.

De acordo com Matos (2016) e Lima (2018), as assimetrias de poder existentes nos contextos organizacionais geram disputas de sentidos definidas em lutas para impor determinados quadros de legibilidade que interferem fortemente na definição daquilo que é percebido como relevante e adequado por um amplo espectro de sujeitos e grupos sociais. Aqueles que têm o poder de definir e impor enquadramentos aos discursos e enunciados que circulam socialmente e institucionalmente, têm também 0 poder de interferir no modo como construímos nosso imaginário e nossas formas de pensar e ler o mundo. Sob esse ângulo, enquadramentos podem, além de produzir alianças e ações coordenadas, permitir a realização de metas e objetivos estratégicos.

Entende-se aqui a estratégia como prática, e não como uma forma de comunicação negativa, oposta à comunicação voltada ao entendimento e ao diálogo. Como argumentam Oliveira e Lima (2012) a perspectiva teórica da estratégia como prática está intrinsecamente embasada na interação social e na compreensão da estratégia como um processo permanente da ação dos atores na sociedade. Além disso, evidencia como as estratégias organizacionais estão em constante relação com aquelas delineadas pelos demais atores sociais, em uma interação negociada que envolve a construção de sentidos e contrassentidos.

8 Do original: "If oppressed groups challenge the supposed neutrality of prevailing assumptions and policies and express their own experiences and perspectives, their demands are seen as biased, as selfish and special interests that deviate from a general and impartial interest. The commitment to an ideal of impartiality makes it difficult to express partiality from the supposedly general point of view, and it also makes it difficult to claim a voice for the oppressed". 
Segundo Baldissera etal. (2020), sentidos são reconstruídos e disputados, organizados e desorganizados em trocas discursivas protagonizadas por sujeitos individuais e coletivos movidos por interesses distintos e, por vezes, contraditórios.

Sob esse aspecto, o sentido construído e disputado na interação é mais do que uma troca de informações - trata-se de confrontação de ideias e de interpretações diferentes, determinando a dinâmica e a orientação de uma ação ou atitude de um ou mais públicos e atores sociais, além de suas dimensões de assimetria, desigualdade e poder.

Isso significaria dizer que a organização resulta de uma constante negociação de sentidos? Toda instituição se assenta sobre um processo de instituição imaginária da sociedade que deriva no modo como nossas crenças embasam práticas e relações que reforçam significados e vínculos de confiança. Uma organização (e sua complexa teia interacional com diferentes públicos) é composta por pessoas que confiam umas nas outras, reforçam essa confiança a partir da missão e dos objetivos coletivos, mantendo-se estável no imaginário e na crença compartilhada e constantemente reforçada. Essa crença coletiva é tácita e fica mais evidente quando situações de crise e ruptura revelam os atores envolvidos, as dissonâncias e tensões ocultas na naturalização das práticas, articulações de poder que emergem junto com acontecimentos não previstos. Em outras palavras, a dimensão simbólica desse imaginário compartilhado fica mais palpável quando um problema coletivo é tematizado, dando origem a públicos organizados em esferas espraiadas (mas nem sempre articuladas) de discussão e debate, que são os sujeitos do processo de formação da opinião pública.

É nas situações de ruptura e de crise que as disputas de sentido deixam entrever as vulnerabilidades constituintes das organizações e de seus discursos. Assim, disputar sentidos é também disputar enquadres, ou seja, nomear (conferir existência) e julgar o que e quem merecem ser dignos de atenção, escuta e consideração. Nomear pode tanto produzir assujeitamento quanto subjetivação, destituição de poder e brecha para a desidentificação. Negociar sentidos implica, em suma, delimitar, fazer aparecer e tematizar vulnerabilidades ligadas ao modo como sujeitos, normas, temporalidades e ações se tornam legíveis e reconhecíveis em um dado contexto e situação. Isso implica que vulnerabilidades são construídas, modeladas, alteradas e superadas socialmente e situacionalmente.

Assim, uma reflexão que almeja evidenciar processos de formação e transformação de públicos e da opinião pública em contextos organizacionais precisa considerar que eles são atravessados e constituídos por inúmeras vulnerabilidades e assimetrias que não pertencem individualmente aos sujeitos. Elas podem se originar de atitudes éticas de indiferença que reverberam sobre um pano de fundo moral que, por sua vez, orienta posicionamentos e julgamentos morais que tendem a inferiorizar e punir. Vulnerabilidades são produzidas juntamente com quadros e enquadres morais que reforçam normas e apagam diferenças. De um lado, enquadramentos moralmente aceitáveis conferem visibilidade, respeitabilidade e reconhecimento; de outro, operações de questionamento desses enquadramentos são responsáveis por evitar a total dissolução do infamiliar dentro do familiar, das singularidades dentro de padrões. Além disso, se os enquadramentos permanecem inquestionáveis, os sujeitos tendem a perder a autoridade sobre sua autonomia narrativa, permitindo que alguém passe a contar, em seu nome, suas histórias e experiências.

Segundo Mafra e Marques (2015), os arranjos institucionais, a cultura e as normatividades definidoras da vida em comum criam sistemas de diferença que constroem e posicionam as pessoas como pertencentes ou não à organização, dignas ou indignas, valiosas ou desprovidas de valor. Vulnerabilidades surgem não só da distribuição desigual de recursos discursivos, políticos e materiais, mas também dos quadros morais tacitamente compartilhados e que servem para avaliar, julgar e tornar visíveis e audíveis sujeitos e coletividades em cenas dissensuais. É nessas cenas que os públicos e a opinião pública se delineiam, fazem figurar singularidades e coletividades, evidenciando uma dinâmica estratégica, assimétrica e interacional. 


\section{CONSIDERAÇÕES FINAIS}

Não seria de todo errado trabalhar as três trilhas aqui apresentadas como modelos hegemônicos na pesquisa sobre opinião pública no âmbito da comunicação. Embora com pontos de contato, origens e perspectivas em comum, elas parecem se desenvolver em espaços opostos. Não se trata apenas de indicar, em cada uma, o que seria o "lugar" da mídia, mas verificar que existem diferenças conceituais até mesmo a respeito do que se entende por isso.

As interseções entre essas tradições de pensamento são problemáticas em termos teóricos e metodológicos. As concepções que orientam uma pesquisa sobre "esfera pública" conversacional são significativamente diferentes de um modelo de ação da mídia na formação do público. Uma das razões dessa dificuldade é, como lembra Blondiaux (2001), a tradução tardia de Mudança estrutural da esfera pública, de Habermas (2011), para o inglês: o texto aparece em 1989, mais de 20 anos depois de sua edição original e quando a tradição anglo-saxônica de pesquisa está plenamente consolidada.

0 modelo de influência destaca a centralidade da mídia, no sentido das instituições, meios e códigos na formação da opinião, enquanto o modelo deliberativo foca a conversação entre as pessoas. Mais do que eixos teóricos distintos, trata-se de concepções epistemológicas diferentes que envolvem, para além dos conceitos, também metodologias e aportes diversos, sem desconsiderarmos suas lacunas e fragilidades.

No caso da perspectiva habermasiana, por exemplo, que embasa uma série de pesquisas sobre opinião pública, acreditamos que uma dimensão que permanece inexplorada na literatura é a forma como esse autor raramente tematiza o modo como o poder e a ideologia alteram as condições de troca racional de argumentos, de justificação para alcance do entendimento. Quando Habermas menciona, em Teoria da ação comunicativa (1987), algo que pode ser chamado de "comunicação sistematicamente distorcida", ele tende menos a apontar os "sistemas" ou "subsistemas" como causas de ruptura no agir comunicativo, e mais as condições que são estabelecidas para as trocas comunicativas. Essa reflexão é explorada por alguns críticos que mencionam as vulnerabilidades dos interlocutores quando expostos a uma naturalização das condições assimétricas de interação (Bohman, 2000; Gross, 2010). A camuflagem das desigualdades faz com que as pessoas acreditem que participam de uma esfera pública, quando, na verdade, não são informadas sobre alterações nas condições de comunicação, ou seja, no pano de fundo ao qual se remetem os interlocutores. Dito de outro modo, se o pano de fundo das trocas é alterado, e diante da necessidade de as pessoas se desvenciliarem de situações morais de injustiça, elas recebem falsa orientação acerca da situação de troca e acabam aceitando um pacto comunicativo falso.

Apesar de ter desenvolvido apenas os contornos dessa ideia, Habermas $(1982,1970)$ aponta que há uma violência estrutural na comunicação sistematicamente distorcida: quando um problema coletivo é tematizado por um público, há a demarcação de convicções que se mostram efetivas para a legitimação das ações de apenas alguns participantes. Os demais envolvidos nas discussões recebem uma falsa orientação acerca do que devem fazer e da própria situação de troca. A distorção opera assim como um bloqueio que age muitas vezes de forma despercebida, mas em outros casos de forma mais explicitamente. São restrições estruturais que limitam a expressão dos públicos e da opinião pública. Habermas (1982) fala na imposição de "barreiras despercebidas" no processo de formação da opinião pública, apoiadas em uma razão cínica que só funciona em condições de assimetria e desigualdade entre os interlocutores.

Seja qual for o eixo teórico-epistemológico adotado para uma abordagem da opinião pública, é importante localizar as disputas de sentido, as assimetrias de poder, as vulnerabilidades e as desigualdades contextuais e institucionais como dimensão central de análise. E, não raro, para evidenciarmos como a estrutura para a comunicação é internamente violada, 
precisamos explicitar as condições de diálogo são cerceadas por códigos publicamente reconhecidos (mas impostos) e por normas implícitas que só se dão a ver nas contradições, nas lacunas e nas inconsistências dos fenômenos que estudamos.

\section{REFERÊNCIAS}

ANSELMINO, Natalia Raimondo; REVIGLIO, María Cecilia; DIVIANI, Ricardo. Preguntas para una aproximación crítica a la categoría esfera pública en tiempos de Facebook. In: FAUSTO NETO, Antonio; ANSELMINO, Natalia Raimondo; GINDIN, Irene Lis (ed.). Relatos de investigaciones sobre mediatizaciones. Rosário: Universidad Nacional de Rosario, 2015, p.212-224.

BALDISSERA, Rudimar; SARTOR, Basilio; ROSSATO, Jean. Comunicação e interesse público: a triangulação "iniciativa privada poder público - comunidade". Revista Alceu, Rio de Janeiro, v.16, n.32, p.207-224, 2016.

BALDISSERA, Rudimaretal. O que é opinião pública? Maputo: Escolar Editora, 2020. No prelo.

BERELSON, Bernard. Democratic theory and public opinion. Public Opinion Quarterly, Oxford, v.16, n.3, p.313-330, 1952.

BLONDIAUX, Loïc. Les théories contemporaines de l'opinion publique : un retour aux "classiques"? Hermès, Paris, n.31, p.9-20, 2001.

BLUMER, Herbert. The mass, the public, and public opinion. In: BERELSON, Bernard; JANOWITZ, Morris (org.). Reader in public opinion and communication. New York: The Free Press, 1967. p.43-50.

BOHMAN, James. When water chokes: ideology, communication, and practical rationality. Constellations, Hoboken, v.7, n.3, p.382-392, 2000.

CHAMPAGNE, Patrick. Formar a opinião. Petrópolis: Vozes, 1998.

CHAMPAGNE, Patrick. La double dépendance: quelques remarques sur les rapports entre les champs politique, économique et journalistique. Hermès, Paris, v. 3-4, n. 17-18, p.215-229, 1995.

CHANG, Chingching. Opinions from others like you: the role of perceived source of similarity. Media Psychology, Abingdon, v.14, n.4, p.415-441, 2011.

CHAPPELL, Zsuzsanna. Deliberative democracy. a critical introduction. London: Palgrave Macmillan, 2012.

COOLEY, Charles Horton. The theory of public opinion. In: COOLEY, Charles Horton. Social organization. New York: Charles Scribner's Sons, 1909. p.121-134.

CRUZ, Cassiana Maris Lima. A comunicação organizacional e a formação da opinião pública. In: CONGRESSO BRASILEIRO DE CIÊNCIAS DA COMUNICAÇÃO, 30., 2007, Santos. Anais [...]. Santos: Universidade Santa Cecília, 2007.

DAHLGREN, Peter. In search of the talkative public: media, deliberative democracy and civic culture. Javnost The Public, Abingdon, v.9, n.3, p.5-25, 2002.

DAVISON, Philips. The third-person effect in communication. Public Opinion Quarterly, Oxford, v.47, n.1, p.1-15, 1983. 
DEAN, Jodi. Why the net is not a public sphere. Constellations, Hoboken, v.10, n.1, p.95-112, 2003.

DEWEY, John. La opinión pública y sus problemas. Madrid: Morata, 2004.

ELIASOPH, Nina. Making a fragile public: a talk-centered study of citizenship and power. Sociological Theory, Ann Arbor, v.14, n.3, p.262-289, 1996.

ESTEVES, João Pissarra. Opinião pública. In: CORREIA, João Carlos; FERREIRA, Gil Baptista; ESPÍRITO SANTO, Paula do (org.). Conceitos de comunicação política. Covilhã: LabcomBooks, 2010. p.21-32.

FARIAS, Luiz Alberto de; LEMOS, Else; REBECCHI. Claudia Nociolini (org.). Opinião pública, comunicação e organizações: convergências e perspectivas contemporâneas. São Paulo: Abrapcorp, 2020.

FERREIRA, Fernanda Vasques. Raízes históricas do conceito de opinião pública em comunicação. Em debate, Belo Horizonte, v.7, n. 1, p.50-68, 2015.

FIGUEIREDO, Rubens; CERVELLINI, Sílvia. Contribuições para o conceito de opinião pública. Opinião Pública, Campinas, v.3, n.3, p.171-185, 1995.

FRASER, Nancy. Rethinking the public sphere: a contribution to the critique of actually existing democracy. Social Text, Durham, n.25-26, p.56-80, 1990.

FRIEMEL, Thomas N. Influence versus selection: a network perspective on opinion leadership. International Journal of Communication, Los Angeles, v.9, p.1002-1022, 2015.

GAMSON, William A.; MODIGLIANI, Andre. Media discourse and public opinion on nuclear power: a constructionist approach. American Journal of Sociology, Chicago, v.95, n.1, p.1-37, 1989.

GASTIL, John. Political communication and deliberation. London: Sage, 2008.

GERBER, Alan S. etal. Who wants to discuss vote choices with others? Public Opinion Quarterly, Washington, DC, v.77, n. 2, p.474-496, 2013.

GINGRAS, Anne-Marie. L'Impact des communications sur les pratiques politiques. Hermès, Paris, v.3-4, n.17-18, p.35-47, 1995.

GOMES, W. Opinião pública política hoje: uma investigação preliminar. In: FAUSTO NETO, Antônio etal. (orgs.). Práticas mediáticas e espaço público. Porto Alegre: EdiPUCRS, 2001.

GOMES, Wilson; MAIA, Rousiley C. M. Comunicação e democracia: problemas e perspectivas. São Paulo: Paulus, 2008.

GROSS, Alan G. Systematically distorted communication: an impediment to social and political change. Informal Logic, Windsor, v.30, n.4, p.335-360, 2010.

HABERMAS, Jürgen. A reply to my critics. In: THOMPSON, John B.; HELD, David (eds.). Habermas: critical debates. Cambridge: MIT Press, 1982. p.219-283. 
HABERMAS, Jürgen. Further reflections on the public sphere. In: CALHOUN, Craig J. (ed.). Habermas and the public sphere. London: MIT Press, 1992. p.421-461.

HABERMAS Jürgen. Mudança estrutural na esfera pública. São Paulo: Editora Unesp, 2011.

HABERMAS, Jürgen. On systematically distorted communication, Inquiry v.13, 1970, p.205-218.

HABERMAS, Jürgen. The theory of communicative action: lifeworld and system, a critique of functionalism reason. Boston: Beacon Press, 1987. v.2

HENRIQUES, Márcio Simeone. Dinâmica dos públicos e da opinião pública na construção da influência: estudo de caso no contexto dos protestos de junho de 2013. In: CONGRESSO BRASILEIRO DE CIÊNCIAS DA COMUNICAÇÃO, 38., 2015, Rio de Janeiro. Anais [...]. Rio de Janeiro: Universidade Federal do Rio de Janeiro, 2015.

HERBST, Susan. History, philosophy, and public opinion research. Journal of Communication, Hoboken, v.43, n.4, p.140-145, 1993.

LAZARSFELD, P. A opinião pública e a tradição clássica. In: STEINBERG, Charles S. (org.). Meios de comunicação de massa. São Paulo: Cultrix, 1975. p.45-62.

LIPPMANN, Walter. Opinião Pública. Petrópolis, RJ: Vozes, 2009.

LIMA, Fábia Pereira. Teorias da comunicação, transferência do conhecimento e implicações na subserviência dos sujeitos nas organizações. Organicom, São Paulo, v.15, n.28, p.287-298, 2018.

LONGHI, Carla Reis. Origens do conceito de opinião pública: um diálogo com Hannah Arendt e Jurgen Habermas. Comunicação e Sociedade, São Bernardo do Campo, v.28, n.46, p.44-56, 2006.

MAFRA, Rennan Lanna Martins; MARQUES, Ângela Cristina Salgueiro. Diálogo e organizações: cenas de dissenso e públicos como acontecimento. In: MARQUES, Ângela Cristina Salgueiro; OLIVEIRA, Ivone de Lourdes (orgs.). Comunicação Organizacional: dimensões epistemológicas e discursivas. Belo Horizonte: Fafich/UFMG, 2015. p. 185-193.

MAIA, Rousiley C. M. etal. Conversação e deliberação sobre questões sensíveis: um estudo sobre o uso das razões que circulam nos media. Galáxia, São Paulo, n. 34, p.55-72, 2017.

MANSBRIDGE, Jane. The long life of Nancy Fraser's "rethinking the public sphere". In: BARGU, Banu; BOTTICI, Chiara (eds.). Feminism, capitalism, and critique. London: Palgrave Macmillan, 2017. p.101-118.

MARQUES, Francisco Paulo Jamil Almeida etal. 0 que significa "opinião pública"?: um estudo sobre os diferentes sentidos do termo nos editoriais do jornal O Estado de S. Paulo. Estudos em Comunicação, Covilhã, v.1, n.25, p.53-78, 2017.

MARQUES, Francisco Paulo Jamil Almeida. Debates políticos na internet: a perspectiva da conversação civil. Opinião Pública, Campinas, v.12, n. 1, p.164-187, 2006. 
MARQUES, Rafael Borges; ALMEIDA, Cristóvão Domingos de. Outros caminhos para a opinião pública em relações públicas. In: CONGRESSO BRASILEIRO DE CIÊNCIAS DA COMUNICAÇÃO, 38., 2015, Rio de Janeiro. Anais [...]. Rio de Janeiro: Universidade Federal do Rio de Janeiro, 2015.

MATOS, Heloiza. $O$ processo discursivo de formação da opinião pública. In: SOUSA, Mauro Wilton de; CORREA, Elizabeth Saad (orgs.). Mutações no espaço público contemporâneo. São Paulo: Paulus, 2014., p.137-162.

MATOS, Heloiza. Opinião pública e conversação cívica. In: MARQUES, Ângela Cristina Salgueiro etal. Esfera pública, redes e jornalismo. Rio de Janeiro: E-papers, 2009. p.107-122.

MATOS, Heloiza. Pesquisas em comunicação pública e política: vertentes teóricas e metodológicas. São Paulo: ECA-USP, 2016.

MENÉNDEZ, María Cristina. Política y medios en la era de la información. Buenos Aires: La Crujía, 2009.

MITRA, Ananda. Marginal voices in cyberspace. New Media and Society, Thousand Oaks, v.3, n.1, 2001, pp.29-48.

MORA Y ARAUJO, Manuel. El poder de la conversación: elementos para una teoría de la opinión pública: tomo I: la opinión pública. 2. ed. Buenos Aires: La Crujía, 2012.

MUTZ, Diana C.; YOUNG, Lori. Communication and public opinion: plus ça change? Public Opinion Quarterly, Oxford, v.75, n.5, p.1018-1044, 2011. Edição especial

NERONE, John. The media and public life: a history. London: Polity, 2015.

NIR, Lilach. Motivated reasoning and public opinion perception. Public Opinion Quarterly, Oxford, v.75, n.3, p.504-532, 2011.

OLIVEIRA, Ivone de Lourdes; LIMA, Fábia Pereira (orgs.). Propostas conceituais para comunicação no contexto organizacional. São Caetano do Sul: Difusão Editora, 2012.

PAPACHARISSI, Zizi. The virtual sphere: the internet as a public sphere. New media and society, Thousand Oaks, v.4, n.1, p.9-27, 2002.

PETERSEN, Michael Bang; SLOTHUUS, Rune; TOGEBY, Lise. Political parties and value consistency in public opinion formation. Public Opinion Quarterly, Oxford, v. 74, n.3, p.530-550, 2010.

RIGOTTI, Sebastián. Opinión pública y procesos de identificación. Questión, La Plata, v.1, n.33, p.1-15, 2012.

PRICE, Vincent. Social identification and public opinion: effects of communicating group conflict. Public Opinion Quarterly, Oxford, v.53, n.2, p.197-224, 2011.

RIUTORT, Philippe. Sociologie de la communication politique. Paris: La Découverte, 2007.

SÁNCHEZ VILELA, Rosario. Como hablamos de la democracia? narrativas mediáticas de la política en el Uruguay. Montevideo: Universidad Católica del Uruguay: Manosanta, 2014. 
SAVIGNY, Heather. Public opinion, political communication and the internet. Politics, Thousand Oaks, v.22, n.1, p.1-8, 2002.

SCHÄFER, Mike S.; TADDICKEN, Monika. Mediatized opinion leaders: new patterns of opinion leadership in new media environments. International Journal of Communication, Los Angeles, v.9, p.960-981, 2015.

SCHUDSON, Michael. Por que a conversação não é a alma da democracia? Famecos, Porto Alegre, v.8, n.14, p.19-31, 2001.

SENA, Nilza Mouzinho de. Espaço público, opinião e democracia. Estudos em Comunicação, Covilhã n.1, p.270-304, 2007.

SIGNATES, Luiz. Epistemologia da comunicação na democracia: a centralidade do conceito de comunicação na análise dos processos políticos. Novos Olhares, São Paulo, v.1, n.1, p.7-18, 2012.

SILVA, Daniel Reis. John Dewey, Walter Lippmann e Robert E. Park: diálogos sobre públicos, opinião pública e a importância da imprensa. Revista Fronteiras, São Leopoldo, v.18, p.57-68, 2016.

SOUZA, Scarlet A. V. D. A função política e a teoria da opinião pública. In: CONGRESSO BRASILEIRO CIENTÍFICO DE COMUNICAÇÃO ORGANIZAÇÃO E DE RELAÇÕES PÚBLICAS, 13., 2019, São Paulo. Anais [...]. São Paulo: Faculdade Cásper Líbero, 2019.

SPEIER, Hans. $O$ desenvolvimento histórico da opinião pública. In: STEINBERG, Charles (org.). Meios de comunicação de massa. São Paulo: Cultrix, 1972, p.127-148.

STROMER-GALLEY, Jennifer. New voices in the public sphere: a comparative analysis of interpersonal and online political talk. The Public, Abingdon, v.9, n.2, p.23-41, 2002.

TARDE, Gabriel. A opinião e as massas. São Paulo: Martins Fontes, 1995.

TAVARES, Francisco Mata Machado. Em busca da deliberação: mecanismos de inserção das vozes subalternas no espaço público. Revista Brasileira de Ciência Política, Brasília, n.9, p.39-70, 2012.

TERRA, Carolina Frazon; SOUSA, Gisela Maria Santos Ferreira de. Opinião pública em tempos de mídias sociais: midiatização, comunicação desintermediada e memes. In: FARIAS, Luiz Alberto; LEMOS, Else; REBECHI, Claudia Nociolini (orgs.). Opinião pública, comunicação e organizações. São Paulo: Abrapcorp, 2020.

THOMPSON, John B. O escândalo político: poder e visibilidade na era da mídia. Petrópolis, RJ: Vozes, 2002.

VALDETTARO, Sandra. Opinión pública y escenarios mediales. Anuário de la Faculdad de Ciência Política y Relaciones Internacionales, Rosário, v.1, p.1-6, 1998.

WEBER, Maria Helena. Nas redes de comunicação pública, as disputas possíveis de poder e visibilidade. In: WEBER, Maria. Helena; COELHO, Marja Pfeifer; LOCATELLI, Carlos (orgs.). Comunicação pública e política: pesquisa e práticas. Florianópolis: Editora Insular, 2017. p. 23-56.

WOJDYNSKI, Bartosz W.; RIFFE, Daniel. What kind of media, and when? public opinion about press coverage of politicians' private lives. Journal of Mass Media Ethics, Abingdon, v.26, n.3, p.206-223, 2011. 
YOUNG, Iris. Comunicação e o outro: além da democracia deliberativa. In: SOUZA, Jessé. Democracia hoje: novos desafios para a teoria democrática contemporânea, Brasília: Editora UnB, 2001. p.365-386.

YOUNG, Iris. Justice and the politics of difference. Princeton: Princeton University Press, 1990.

Artigo recebido em 28/05/2020 e aprovado em 13/10/2020. 